\title{
A Comparison Between Ritual and Conventional Slaughter in Regard to Animal Welfare and Meat Hygienic Quality
}

\author{
Sorin Daniel DAN*, Oana REGET, Marian MIHAIU, Gilad HALBANI, Alexandra LĂPUŞAN \\ Department of Animal Production and Food Safety, University of Agricultural Sciences and Veterinary \\ Medicine, Faculty of Veterinary Medicine, 3-5 Mănăştur Street, 400372, Cluj Napoca, Romania \\ *corresponding author: sorindan@usamvcluj.ro
}

Bulletin UASVM Veterinary Medicine 73(2) / 2016,

Print ISSN 1843-5270; Electronic ISSN 1843-5378

DOI:10.15835/buasvmcn-vm: 12250

\begin{abstract}
The slaughter process in its current form is responsible to numerous physiological impacts on the animal and as a consequence affects the quality of the meat which is produced. The kosher slaughter is performed by a Rabbi (a certified Jewish religious priest) employed by the meat processing facility. The aim was to compare different types of slaughter methods and restraining techniques in order to determine the positive and negative sides of each method and to assess the hygienic quality of the meat produced from this method of slaughter. The information regarding kosher slaughter was gathered from one slaughterhouse located in Israel, Haifa city, and specific aspects related to the conventional slaughter technology, was acquired from a slaughterhouse located in Maramures County, where we critically observed the cattle slaughter technology, with focus on stunning and bleeding steps. In order to compare the hygienic quality of kosher beef with conventional beef the research material consisted by 40 samples of beef, half of the samples were represented by kosher beef and the other half (conventional beef) were used as control. Total viable and Enterobacteriaceae count were performed from the collected samples according with standards methods. In case of conventional slaughter, with respecting of good hygienic practices (GHP), bleeding will not open the esophagus and trachea, preventing thus the possibility of contamination. Stunning performed in conventional slaughter could increase the risk of contamination of carcasses with prions in case of penetration of the skull. In case of kosher meat, the results regarding total plate count revealed values between $2.78 \pm 0.6 \log \mathrm{cfu} /$ $\mathrm{cm}^{2}$ and $3.40 \pm 0.2 \log \mathrm{cfu} / \mathrm{cm}^{2}$. In case of Enterobacteriaceae germs, we noticed that 3 samples shown a negative results. For the rest of the samples, the microbial load ranged between $2.54 \pm 0.62 \mathrm{log} \mathrm{fcu} / \mathrm{cm}^{2}$ and $3.1 \pm 0.32 \log$ $\mathrm{fcu} / \mathrm{cm}^{2}$. In comparison, the conventional meat (control), present an elevated total microbial load, ranged between $4.77 \pm 0.56 \log \mathrm{cfu} / \mathrm{cm}^{2}$ and $5.34 \pm 0.21 \log \mathrm{cfu} / \mathrm{cm}^{2}$. The Enterobacteriacee load ranged between $4.1 \pm 0.56 \operatorname{log~cfu} / \mathrm{cm}^{2}$ and $5.33 \pm 0.2 \log \mathrm{cfu} / \mathrm{cm}^{2}$. Ritual kosher slaughter is a humane way of sacrificing animals for human consumption although there are many parameters which need to be carefully monitored in order to guarantee the welfare of the slaughtered animals. And thus, inherently this method is prone for animal welfare violation. Microbiological risk regarding total plate and Enterobacteriaceae count in case of kosher compared with conventional meat is low.
\end{abstract}

Keywords: ritual slaughter, kosher meat, animal welfare, hygienic quality

\section{INTRODUCTION}

Religious slaughter, or slaughter without stunning, are methods practiced throughout the world where religious rules do not allow stunning. Mostly the Jewish "Shechita" and the Muslim
"Halal". Those traditional slaughter methods are a source of ongoing controversy and debate between religious groups and animal welfare movements. And a debate of this scale, which comes from a very emotional stance on both sides, 
naturally produces a great deal of disinformation. For example, a quantitative research of 2,500 adults showed that on average 3 out of every 5 consumers buy kosher products for the quality of the food rather than for religious reasons (Mintel, 2009). $62 \%$ of participants have answered that they buy kosher for "food quality", 51\% marked "general healthfulness" as a reason and "food safety" was elected as the $3^{\text {rd }}$ most common answer. Only $14 \%$ of participants wrote down "religious reasons" as a reason for their selection of meat or dairy source. The market of kosher food is considered strong and growing in the U.S and kosher food sales of meat, dairy and fish summed up to roughly $\$ 17$ billion in the U.S alone, a $64 \%$ increase since 2003. The common perception in Israel is that kosher slaughter is the most humane way of killing an animal for consumption.

According to Jewish slaughter laws, lesions in the carcass which "might have prevented the animal from living for a period of 12 months" will make the carcass be defined as "Teref" and not suitable for human consumption. Meat that is labeled as kosher has undergone a series of inspections where the inspector "bodek" has to examine the carcass for different pathological conditions: missing organs, adhesive tissue of internal organs, torn organ walls, bone fractures and perforated organs. Therefore to some extent, the kosher slaughter ensures the animal's welfare prior to slaughter. After the animal was processed into consumable meat some of the blood trapped in the tissue is removed by applying salt to the meat for a minimum of one hour before packaging and thus, presumably, provides an addition layer of antimicrobial disinfection of kosher meat (The Torah, Deut. 12:21).

This study will try to assess the welfare of kosher slaughtered animals and food properties from a scientific-veterinary viewpoint by comparing it to the conventional methods which involved stunning prior to bleeding out. The aim is to compare different types of slaughter methods and restraining techniques in order to determine the positive and negative sides of each method.

\section{MATERIALS AND METHODS}

The information regarding kosher slaughter was gathered from one slaughterhouse located in Israel, Haifa city, where we performed an observation on the process of ritual kosher slaughter as it is done in Israel. Similarly, specific aspects related to the conventional slaughter technology, was acquired from a slaughterhouse located in Maia Mare, Maramureş County, where we critically observed the cattle slaughter technology, with focus on stunning and bleeding steps.

In order to compare the hygienic quality of kosher beef with conventional beef the research material consisted in 20 samples of beef, where half of the samples were represented by kosher beef and the other half (conventional beef) were used as control. Every sample was represented by 3-4 beef slices. The samples were collected from hypermarkets in the Cluj County. After acquiring, the samples were transported in thermic insulated bags $\left(4 \ldots 6^{\circ} \mathrm{C}\right)$, in less than $30 \mathrm{~min}$., to the laboratory of Food Inspection and Control, within Faculty of Veterinary Medicine Cluj-Napoca. The bacteriological determinations were made in maximum one hour from their receiving in the laoratory.

\section{Sample preparation}

Samples of each carcass were homogenized together for $120 \mathrm{sec}$. in $100 \mathrm{ml} 0.1 \%$ buffered peptone water and $0.85 \%$ sodium chloride solution in a stomacher Easymix (AES Chemunex, Bruz, FR). Serial dilutions were aseptically prepared and plated onto various selective and differential media. In order to compare the microbiological quality of kosher beef versus conventional beef we were obliged to process kosher meat in experimental condition. Based on the protocol employed by traditional kosher slaughter plants, 20 samples of beef were obtained from hypermarkets around Cluj-Napoca and undergone the kosher meat treatment. Two samples from each piece of meat were taken where one was immersed in water for 30 minutes and then salted $(\mathrm{NaCl} 3 \%)$ and left on an angular surface for 1 hour in order to let the blood drain out. The second sample taken from each piece of meat was used as control.

\section{Microbiological analysis}

Suspensions were manually poured on plate count agar (Merck, KGaA, Darmdstadt, Germany) and violet red bile glucose agar (VRBD agar, Merck, KGaA, Darmdstadt, Germany). In order to assess the microbial load we used standardize methods: aerobic plate count - SR EN ISO 4833/2003; Enterobacteriaceae count - SR ISO 21528/2007. Manual counting was applied. In order to identify Enterobacteriaceae members we performed 
biochemical confirmation tests: oxidase and fermentation (bioMérieux SA Marcy l'Etoile, France).

\section{Statistical analysis}

All statistical analysis was performed using the Origine 8.5 software (OriginLab Corporation, Northampton, USA. The experiment regarding the evaluation of the decontamination effect of $\mathrm{NaCl}$ addition to the kosher meat was repeated three times, and the results were interpreted on the basis of individual average determination, expressed according to the standard deviation $(n=3)$. The bacterial counts (CFU/g) are $\log _{10}$ transformed for a normal distribution of the results. The integrated statistic test used in order to realize the statistic interpretation of our results was the mono-factorial categorical analysis ANOVA, using an $\alpha$-value of 0.05 as a level of significance. To evaluate significant differences in TPC and Enterobacteriaceae count between kosher and conventional beef samples, one-way analysis of variance (ANOVA) was performed.

\section{RESULTS AND DISCUSSION}

The welfare of cows slaughtered in kosher ritual

The animals arrive on trucks to the slaughterhouse and are unloaded into a tunnel which ends in the resting area where they will spend the next 12 hours resting and feeding. We do not witness an unexpected level of stress in cows which are transported and relocated into an unfamiliar environment. According to the Israeli law of animal protection of 2006 it is stated that "A large ruminant will not be loaded on a vehicle intended for transportation if the animal sustains an injury which affects its welfare during transport" and the religious Jewish law states that an animal must appear healthy enough to survive for 12 months in order to be considered worthy of human consumption.
The restraining device used for slaughter is the position was the rotating box of the Weinberg model where the animal is rotated 180 degrees into a dorsal recumbence position prior to neck cutting.

Concerning the animal's welfare and stress levels, only one animal showed signs of prolonged consciousness of over one minute and 2 animals vocalized and the rest went quietly into the pen and did show signs of resistance or unexpected stress until the box began to turn and the animal began to show minimal signs of struggle (table 1). The "Shochet" (slaughterer) stretches the neck of the animal, applied hot water with a small amount of alcohol in order to reduce the risk of $E$. coli and Salmonella contamination of the carcass. The "Chalaf" (slaughter knife) is washed with water, the cut is then performed with a few quick knife movements and the animal is turned a little backwards to be ejected from the pen, bleed out and shackled.Followin $g$ the cut and exanguination the cow is released and ejected from the restraint to finish bleeding.

\section{The welfare of cows slaughtered in conventional slaughter}

From an animal welfare point of view post stunning slaughter is preferable to kosher slaughter due to the low amount of variables which needed to be controlled and supervised in order to guarantee the welfare of the slaughtered animals. But on the other hand, post stunning slaughter might give the public the false idea that just because the animals are stunned it means that their welfare is guaranteed. The actual welfare of animals during slaughter has more to do with efficient plant management which emphsize right handling, functional equipment and facilities and trained proffesional workers who cares about doing their job properly. After the cows enter the stunning box, a trained operator will aply the

Table 1. Time until collapse and eye rollback after kosher slaughter

\begin{tabular}{ccc} 
& Group 1 (seconds) & Group 2 (seconds) \\
\hline Average time & 17 & 33 \\
\hline Shortest time & 10 & 15 \\
\hline Longest time & 38 & 82 \\
\hline Number of cattle & 10 & 12 \\
\hline Percentage that collapsed within 30 seconds & $94 \%$ & $68 \%$ \\
\hline
\end{tabular}


captive bolt pistol in to the right position for every species. After stunning, it's mandatory to assesess if the animals were efectively stunned. This is based on the following aspects: animal immediately falls down; tongue sticks out of mouth and is limp; eyes are fully open; pupils are fixed and fully dilated; there is no blinking reflex of fast eye movements (nystagmus); there is no rhythmic breathing.

This phase (the tonic phase) typically lasts $10-20 \mathrm{~s}$ and is followed by a period of involuntary kicking movements of its legs (the clonic phase). After stunning the animal is ejected from the stunning box automatically, and then immediately shackled. Then, next step of slaughter technology, bleeding must be realized within 40-50 sec., in order to not allow the animal to recover. Is important to sever both carotid arteries and both jugular veins, or theblood vessels from which they arise nearer the heart. Chest sticking may have advantages in promoting faster exsanguination. In case of cutting only one carotid will prolong the time to death.

Microbiological quality of kosher meat versus conventional meat

In case of kosher meat, the results regarding total plate count revealed values between $2.78 \pm 0.6$ $\log \mathrm{cfu} / \mathrm{cm}^{2}$ and $3.40 \pm 0.2 \log \mathrm{cfu} / \mathrm{cm}^{2}$ (figure $1)$. These values are much below the maximum admitted level according to the provisions of Reg. CE 1441/2007 (5.0 log cfu/ $\mathrm{cm}^{2}$ ), in case of bovine carcasses. Becouse there isn't maximum levels in case of fresh meat, only in case of minced meat $\left(\mathrm{m}=5 \times 10^{5}, \mathrm{M}=5 \times 10^{6} \mathrm{cfu} / \mathrm{g}\right)$ we consider that this load reflect a very good microbial quality. The lower level of microorganisms in carcasese obtained from animals slaughter according to ritual techniques, can be explained by the lower amount of blood in muscle, wich is an important major factor affecting the microbial spoilage (Nakyinsige et al., 1999; Lerner, 2009). These results are similar with other findings reported by Azad et al. (2016) in goats, Sabow et al. (2015) in goats, Addeen et al. (2014) and Ali et al. (2011) in broiler chicken who found reduced levels of bacteria in meat obtained from animals slaughtered using ritual methods.

In case of Enterobacteriaceae germs, we noticed that 3 samples shown a negative results (figure 2). For the rest of the samples, the microbial load ranged between $2.54 \pm 0.62 \log \mathrm{fcu} /$ $\mathrm{cm}^{2}$ and $3.1 \pm 0.32 \log \mathrm{fcu} / \mathrm{cm}^{2}$. These values are below the maximum admitted level according to the provisions of Reg. CE 1441/2007 (3.5 log cfu/ $\mathrm{cm}^{2}$ ), in case of bovine carcasses.

In comparison, the conventional meat (control), present an elevated total microbial load, as is depicted in figure 3. Total plate count ranged between $4.77 \pm 0.56 \log \mathrm{cfu} / \mathrm{cm}^{2}$ and $5.34 \pm 0.21$ $\log \mathrm{cfu} / \mathrm{cm}^{2}$. Based on statistical calculations we established that the microbial load was reduces by 1.67 and $2.42 \log$ (47-268 times). Also,

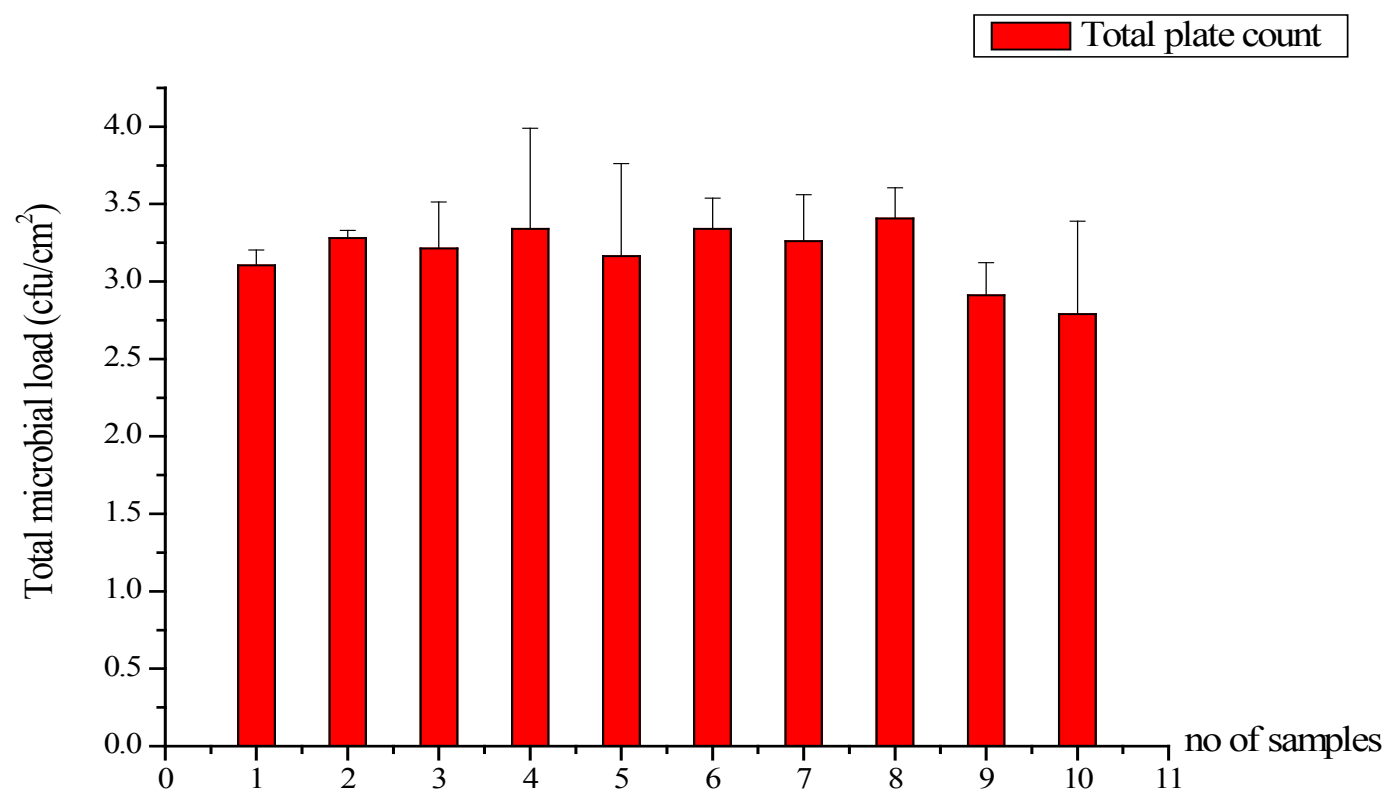

Fig. 1. Total plate count in case of kosher beef $(n=3)$ 
between the results obtained in the case of kosher compared with conventional meat, we noticed significant differences $(\mathrm{p}<0.05)$. Similar results were reported by Hajmeer et al. (1999), in wich aerobic plate count decrease in case of $80 \%$ of analysed samples, but the magnitude of reduction was lower $\left(0.11 \log \mathrm{CFU} / \mathrm{cm}^{2}\right)$ and coliform load was reduced only by $0.09 \log \mathrm{CFU} / \mathrm{cm}^{2}$.

Similar results were obtained in case of Enterobacteriaceae load performed from conventional beef (figure 4).

The values ranged between $4.1 \pm 0.56 \mathrm{log} \mathrm{cfu} /$ $\mathrm{cm}^{2}$ and $5.33 \pm 0.2 \log \mathrm{cfu} / \mathrm{cm}^{2}$. Based on statistical calculations we established that the microbial load was reduces by 1.32 and $2.3 \log$ Also, between the results regarding Enterobacteriaceae load obtained in the case of kosher compared with conventional meat, we noticed significant differences $(\mathrm{p}<0.05)$.

\section{CONCLUSIONS}

In case of conventional slaughter, with respecting of good hygienic practices (GHP), bleeding will not open the esophagus and trachea, preventing thus the possibility of contamination. Stunning performed in conventional slaughter

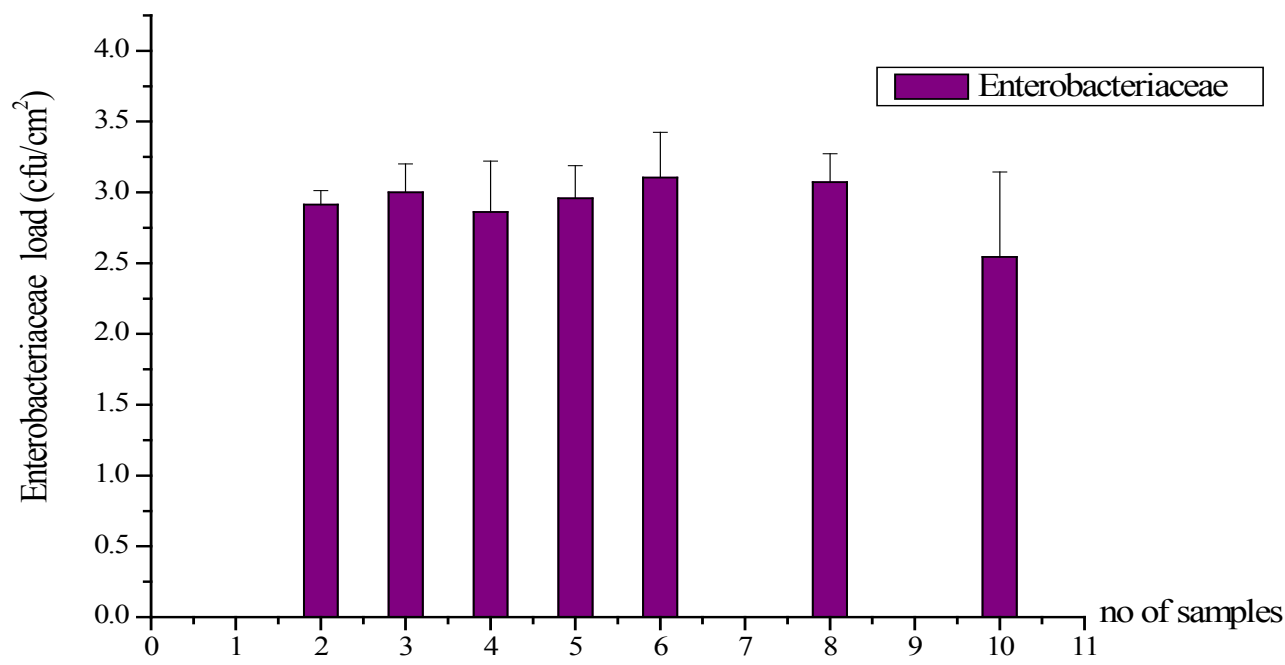

Fig. 2. Enterobacteriaceae count in case of kosher beef $(n=3)$

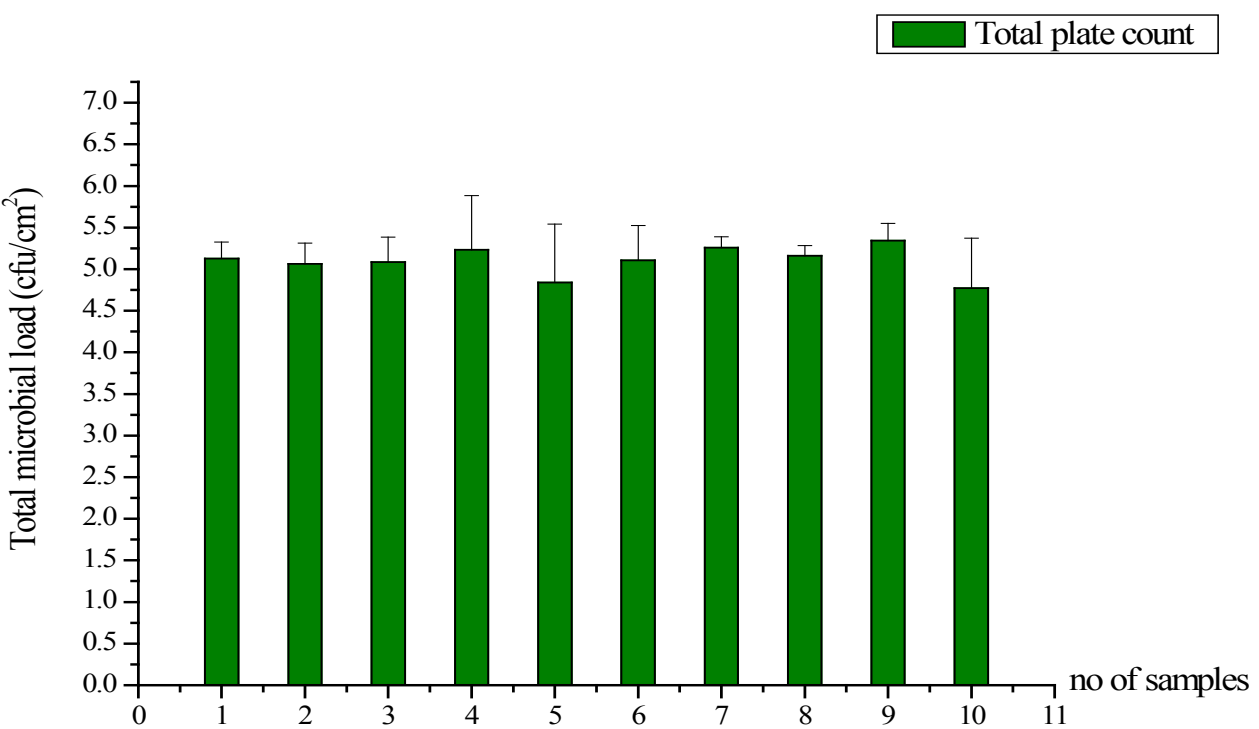

Fig. 3. Total plate count in case of conventional beef $(n=3)$ 


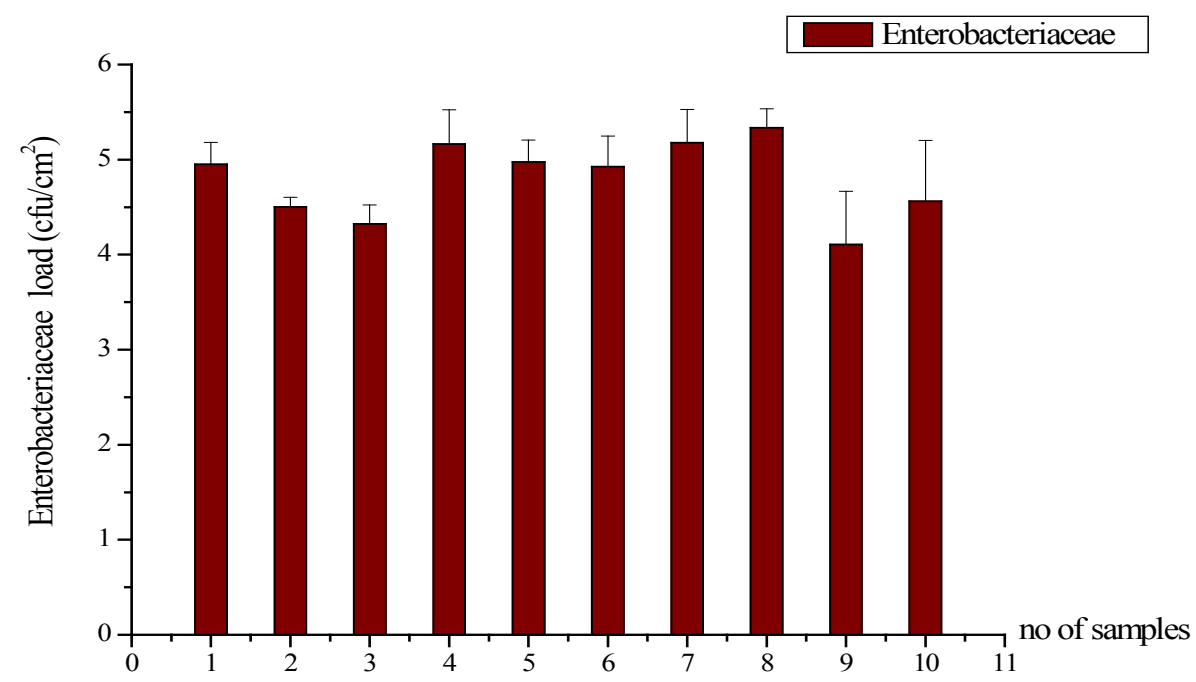

Fig. 4. Enterobacteriaceae count in case of conventional beef $(n=3)$

could increase the risk of contamination of carcasses with prions in case of penetration of the skull. Ritual kosher slaughter is a humane way of sacrificing animals for human consumption although there are many parameters which need to be carefully monitored in order to guarantee the welfare of the slaughtered animals. And thus, inherently this method is prone for animal welfare violation. Regarding meat quality, severing the trachea and esophagus during ritual slaughter holds the possibility of contamination of carcasses. On the other hand, strict Jewish laws regarding the condition of the animals where diseased animals are not allowed to be slaughtered for human consumption (as done in conventional slaughter) could prevent many other hazardous situations. Microbiological risk regarding total plate and Enterobacteriaceae count in case of kosher compared with conventional meat is low, but Kosher meat consumers must be aware of the elevated levels of sodium in the meat in regard to cardiovascular diseases.

\section{REFERENCES}

1. Addeen A, Benjakul S, Wattanachant S, Maqsood S (2014). Effect of Islamic slaughtering on chemical compositions and post-mortem quality changes of broiler chicken meat. Int Food Res J 21: 897-907.

2. Ali A, Abdalla H, Mahgoub I (2011). Effect of slaughtering method on the keeping quality of broiler chickens' meat. Egypt Poult Sci 31: 727-736.
3. Commission Regulation No $1441 / 2007$ of 5 December 2007 amending Regulation No 2073/2005 on microbiological criteria for foodstuffs.

4. Hajmeer MN, Marsden JL, Crozier-Dodson BA, Basheer IA, Higgins JJ (1999). Reduction of Microbial Counts at a Commercial Beef Koshering Facility. J Food Sci 64 (4):719723.

5. Lerner PT (2009). Evaluation of haemoglobin and myoglobin in Poultry slaughtered by stunning and Kosher slaughter. Folia Vet 53: 25-27.

6. Mintel (2009). UK Retail Rankings 2009. London: Mintel.

7. Nakyinsige K, Fatimah A, Aghwan ZA, Zulkifli I, Goh YM, Sazili AQ (2014). Bleeding efficiency and meat oxidative stability and microbiological quality of New Zealand White rabbits subjected to halal slaughter without stunning and gas stun-killing. Asian-Australas J Anim Sci 27: 406-413.

8. Sabow AB, Sazili AQ Zulkifli I, Goh YM, Ab Kadir MZA, Abdull NR, Nakyinsige K, Kaka U, Adeyemi KD (2015). A comparison of bleeding efficiency, microbiological quality and lipid oxidation in goats subjected to conscious halal slaughter and slaughter following minimal anesthesia. Meat Sci 104: 78-84.

9. Sabow AB, Zulkifli I, Goh YM, Abidin Ab Kadir MZ, Kaka U, Imlan JC, Abubakar Abubakar A, Adeyemi KD, Sazili AQ (2016). Bleeding Efficiency, Microbiological Quality and Oxidative Stability of Meat from Goats Subjected to Slaughter without Stunning in Comparison with Different Methods of PreSlaughter Electrical Stunning. Plos One, April 1, 1-18.

10. The Torah, Deuteronomy chapters 12:21. 